\title{
Reward and law basis
}

\begin{abstract}
Any crime any behaviour against our life right and need is persecutable for actual current laws and then any other interaction that leads us to negative directions risks feelings can be called MICRODAMAGE.
\end{abstract}

Volume I Issue I - 2017

Dora Dragoni
Nutritionist, Acupuncture fellow at AMAB, Italy

Correspondence: Dora Dragoni, Medical Doctor, Nutritionist, personal Trainer, Acupuncture Fellow at AMAB, Italy, Tel +39 338 508573I,Email doradragoni@hotmail.com

Received: January 19, 2017 | Published: January 31, 2017

\section{Reward laws}

\section{Reward (neurophysiological) basis}

To understand why having laws is fundamental to lead a right existance, a happy couple life, and a good world equilibrium. The main bad from good distinguishing dates back to the origin of human thought, and is intrinsec on our brain functions: medial reward with life centers basic to breathe and have right bpm heart physiology (IV chakra), then nutritional needs (III chakra), and more than yuan qi necessities, the I+II chakras meaning a right jing equilibrium basis for all qi and shen too (VI+VII chakras). All this are life functions meaning that we have to accomplish them at best and to guarantee them for world. When this is missing dopamine is converted by external stressful stimuli (the BEN) by dopamine beta hydroxylase (see all our bibliography) into negative molecules catecolamines that are cause of stress somatizations, that as all occidental updated ideas its the risk of start of all nowadays categories of disease like atopias, autoimmunities and allergies, endocrino-hormonal dysfunctions, dysautonomias at heart and gastroenterical system, and then all we can relate to wellbeing withdrawal, that is due to an antireward condition to solve. So laws are the main safety way we have to know, have, update and release to guarantee and assure for us, future, society, planet, so that life can be an equilibrated path with beneception for all.

\section{Microdamage}

In this chapter we talk about a new law example related to the so called COLPA GRAVE COLPA LIEVE that are the small errors (or crimes) vs laws that is vs human rights, that summed can become a risk for our existance conditions and life wellbeing, till that they become as an amount like real crimes to be solved and compensated till the elaboration of a safer better lifestyle. Microdamage is for example when we talk positively of us with a friend and this answers in cold way, or in negatively hyronical way, or in acid smiling way; when we send a message to a friend and this answers intentionally with delay; when we are in need and the counterpart falsely declares to be busy or sick again; when we ask for why person missed that help back for us and that person falsely answer; when counterpart always is in need and when we ask a turnover for us too the answer is no now i cannot and then or disappear or again asks toward us; when we truly talk and the person uses false tones to answer; when we have a reward from life and another person is jealous in expressions or in worlds or "trivialize" meaning this that she minimize what we got deserved way; when then we are in discomfort and those persons smile against; when we are forcedly asked to offer what we have as eating or as study notes and persons then fortified pretend some or smile against then such persons when we start understand how friends they are in such ways not as we for sure, then they start talking against envying where we live or what we study since they did a worst life going out having fun drinking wine and kissing everywhere or changing boyfriends even too.

Microdamage is when we are forced to meet persons we don't want we don't like we are not believing as, when we have to talk against our will when we have to smile not as we think when we have to faint to be children when we grew up and so on microdamage is then all this translated into wedded life.....Again after the efforts we did we have to be good children whilst our parents did crimes against, when we have to omit why we have stress signs in our body and soul, when we have to hear that we are false by the husband relatives, when someone says that we have too much cultures and they smile against, when we respect others and they only judge to feel better because thinking to persons younger than us usually makes us feel better, and when we have to give money as gifts to all persons mentioned since we know that coalizations of persons become a concrete damage for anyone, and eventually when we are forced to live in negative ways with error rules and then we are judged for what we are not. All this is microdamage since we cannot call mafia nowadays too what is related to family to false cultures, being culture what elevates us, and we cannot call mafia what is ONLY synchronicity what is ONLY dissacrating not in yet demostrating in scientifical ways, and what is safe sure perceptions of what we know.

The only strategy to solve this is

a. Distinguishing bad from good,

b. Understanding which persons and why have negative behaviors etc and avoid them,

c. In case of reiterations or similar, proceeding toward laws, local laws, elaborating better rules

The main crimes I'm talking about are

a. Ingiuria, when we talk or act against a person in presence, 1 year in jail,

b. Diffamazione, same but person not in presence, 2 years in jail,

c. Molestia, acting maniacally fiscally against a person, seen the grade of crime,

d. Minaccia, talking with damage against a person, 1 year in jail, 
e. Mafia, when 3 or more persons are in that context associated against one, 7-14 years in jail and

f. The worst ones see laws existing and to be relating this to human rights we can say that.

when we accumulate damages our life system is modified negatively from electrical and chemical points of views so that automatically uncultured persons tend to reiterate old previous past wrong behaviors like those mentioned since this is the electrical interactions between brains see their electric field such as registered by EEG and more studies in elaboration and that will explains why human rights are to assure since persons have free will are able to understand and have right willing so that they can and have to choose how to talk and behave toward people if so okay if errors they are judged and solved.

So it's clear what is the human rights human needs situation as told when our reward system life time human faces are active from fisiological point of view from couple interactions too, we are to be safe so that we can and have to choose environments behaviors and any other related to our life love couple and existence chosen to get, we are in fact to be safe and secure that we can lead the life we want need and deserve for these reasons:

a. Local authorities have to a. correctly guarantee right judgments without projecting their inner older overcome life travmas in populations as some extreme oriental chiefs that make laws against drug traffikers or any other minorities crimes that their family genes have as "balanced ethnic budged" to affirm, being this a humanity crime seen the intensity or quantity of persons affected by them seen human rights minimal to be assured for anyone involved $b$. and then assure human needs to be like basic foods seen how agriculture and local fields properties by family nuclei etc and more soil country and similar regulations to get real and

b. World organization have to diffuse that neuroscience is not a theoretical knowledge to be done in a lab to study new receptors for which technologically advanced new economically good targets for drugs companies or similar, but it's a science at service of humanity of which we are part as this life is, and since we are in natural synchro with all the people being as we populating our planet.

So my wellbeing has to involve all wellbeing too, not in only concrete terms but for sure in general ways, so that what i do determines good consequences for all, see how we can synthesize human rights going back to practically ideas to guarantee in terms of human rights.

We can say that as symbol sums up:

a. Food is a human rights being this part of reward system as main one, being this already recognized a human rights, see now whys, see the more we empower people the best they can reach a human standard to live this as told has to be done in local organizations of soils so to permit to anyone a good diet as wrote,

b. Fitness to is a human right see balancing inactivity and hyperwork, and also seen that in nature male and female BMI are often almost similar, guaranteeing this a omogene equilibrium in the couple and family, c. Then mind relaxation time is mandatory to have since its basis to distress in inner way and its fundamental to assure health for person and people since as we described salutogenesis its important to BEFORE assure human needs then permit in a small minor percentual other kind of medial help,

d. Love life is basis for society meaning a theoretical group of persons since people is dynamic see people migrations in order to reach their environment their life their projects to be, love life is basis for our existence for our couple for our family created future for world to evolve to improve to exploit as deserved and in the good way we choose, seen the scientifically studies attesting that..... Being given a standard average life of 70 years we can talk about, missing human love rights means -20 years and assuring them involves +20 years, and this is also the main way to permit to all persons to accomplish genetic needs and destiny to be too, permitting in this way a world balance,

e. Sleep is also to be protected as life need since all life beings have rest time in all their existence seen when cell take good time with lesser activity to balance the previous time what done, seen that sleep quality is the main feature to get good, seen previous parameters in symbol to be there and,

f. Finally extra rewards (+salutogenesis as told) talking about extra rewards we can talk about any pleasant important basic activity related to couple that permit to have a good daily and life balance, and any other couple help by who can be good in the couple chosen way see sincere will and so on (Figure 1).

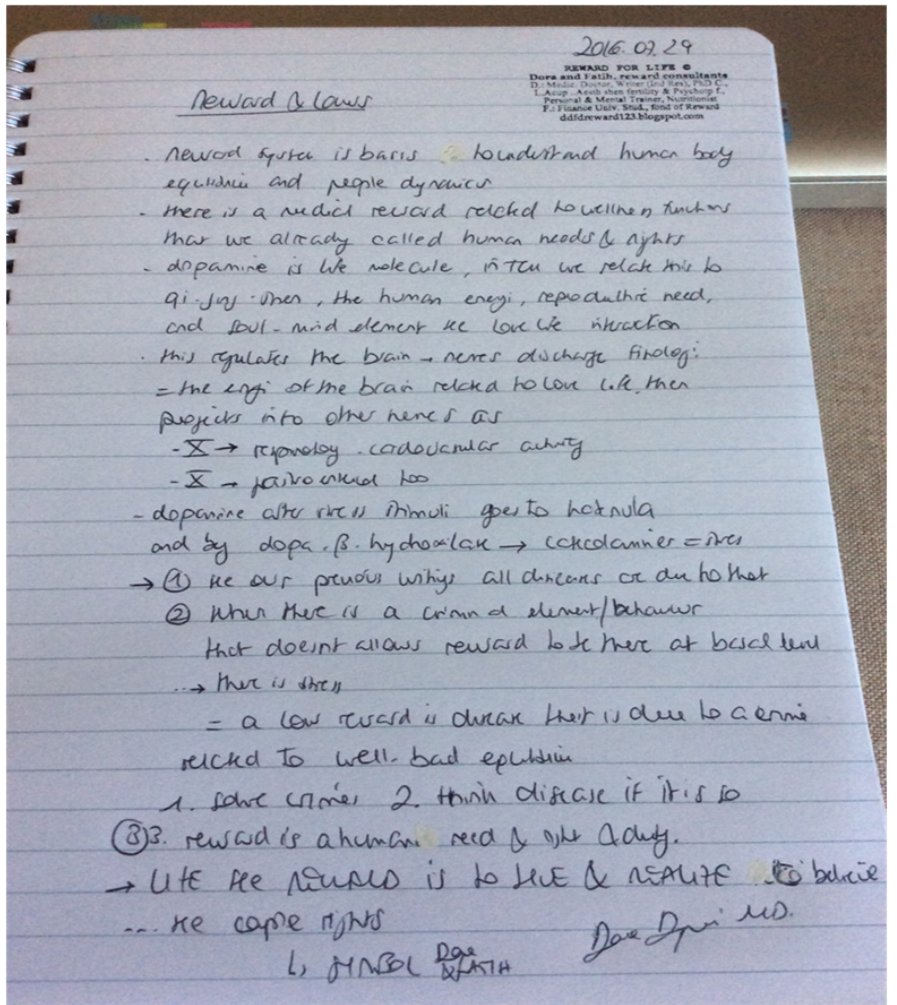

Figure I Rewards \& Law Basis.

\section{Reward importance's}

The main ideas we get from this are also strategies to apply: 
I. Reward is personal, the more reward functions are personal for couple, for partner we love, the more our life can like has to be, easier and better.

II. All lifestyle related to couple has to be choosen by couple since it's the only way to guarantee for future conscious genetic choices related to prole (offspring, children) that has to be as couple want, since till 18 or majority year is influenced by parents, greatly, then its again a couple related matter.

III. Wedding is the way to have a safe couple life since it guarantees the reward privacy, and it's also related to best amounts in quality and quantity of happiness in partnership and to longer better life years.

IV. The dopa gaba rate has always resultantly to be the better we can so that if in previous times then followed the need to repair a cellular life damage, dopamine and relaxing equilibrium practice can be a good system to consciously improve.

V. So another good system to have is: get a right calculation taking into consideration what is negative from an electrical (see how crimes in synchro even are risky negative and stressogens) chemical (which molecules are activated for which reasons) and any other micro-damage as told, intuible and evincible or demostrable...this balance is basis to understand how to proceed to save and get a better life toward any antireward condition.

\section{Perspective for all}

Reward is a human right, a life world need, and all related laws are to assure and guarantee so that world can be as we all want.

\section{Acknowledgements}

None.

\section{Conflict of interest}

Author declares there is no conflict of interest in publishing the article. 